\title{
Decision Making in Financial Markets: A Thematic Review and Discussion
}

\author{
AZHAR IMTIYAZ BISATI"* S.M. IMAMUL HAQUE ${ }^{2}$ \\ UMER JON GANAI ${ }^{3}$ and ISHFAQ GULZAR ${ }^{4}$ \\ 1,2,4Dept. of Commerce, Aligarh Muslim University, Aligarh (U.P), India. \\ ${ }^{3}$ Dept. of Humanities and social sciences, IIT Kanpur (U.P), India.
}

\begin{abstract}
Financial decision making is generally characterized by high degree of risk, uncertainty as well as complexity. Decision making in financial markets takes into consideration a stack of factors including personal, technical and situational factors and above all it necessitates an understanding of human instinct on the top of financial skills. In the broad arena of literature, research studies have proposed two primary themes of decision making-viz. the Rational approach and the Irrational approach. Rational world presupposes being reasonable in every aspect and making unbiased decisions. Irrationality approach contends that investor behaviour is driven by emotions even if they are well informed. This research paper, by using the relevant literature in the field of behavioral decision making and investor psychology, provides an overview of these two distinctive academic doctrines, which clear the way-out as to how in actual world people undertake their decision making. Furthermore, this research paper reviews how behavioral biases can lead to errors in investment decision making.
\end{abstract}

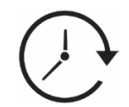

Article History

Received: 04 August 2021

Accepted: 23 September 2021

\section{Keywords}

Behavioral Biases;

Decision Making;

Irrationality;

Rationality.

\section{Introduction}

Decision-making may be described as a deliberate process of selecting a specific alternative from among the accessible options after conducting appropriate rational evaluation. Within a certain environment, this cycle could be perceived as an association between the issue that needs to be addressed and the entity that necessities to address it (Narayan and Corcoran-Perry, 1997). Decision making is often complex, besides the uniformity in decision making is almost impossible and requires a unique art to tackle these complex situations. The reason being the influence of the diverse factors present in the environment. Similarly, financial decision making is often characterized by high degree of uncertainty as well as complexity,

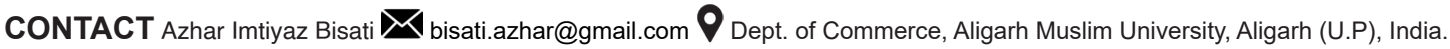
(c) (i)

(C) 2021 The Author(s). Published by Enviro Research Publishers.

This is an $\partial$ Open Access article licensed under a Creative Commons license: Attribution 4.0 International (CC-BY).

Doi: http://dx.doi.org/10.12944/JBSFM.03.01-02.06 
as investors behavior fluctuate from one to other in all facets. In this manner an effective decision making in stock market takes under consideration a stack of factors including personal factors, technical factors and situational factors and requires an understanding of the human nature on top of financial skills. Moreover, empirical confirmation from psychological studies reveal that people perceive each of their decision to be novel and that an ideal investment choice for one investor may not fit another one, as their investment objectives, and risk tolerance differ. Sanglier et al. (1994) illustrates that even if a similar set of information is received by different investors, each investor will have distinct interpretation of the same data. These differing interpretations will prompt differentiated investor behaviors which will subsequently impact their decision making in financial markets. Since investors decipher the acquired facts in their own way, every investor will settle on another choice.

In the broad arena of literature, research has proposed two fundamental models of decision making. One is the rational model based on the norms of homo economicus and Expected Utility Theory (EUT). The other one is irrational model guided by the Prospect Theory and Bounded Rationality assumptions. Rational decision making theory asserts a structured and reasonable thought process, implying that an investor has access to all sorts of statistics pertaining to that specific stock. Rational investor conducts exhaustive searches and is unbound in terms of capacity and knowledge. Hence, taking optimal rational decision is a very calculated phenomenon. This eminent rationality hypothesis was long endorsed by the academic community in finance due to its prosperity, effortlessness, and success to seize the stock price movements. Nonetheless, as the time passed the assumption of rationality invited a severe criticism by a large academic community. The critique has been levelled in terms of both the explanatory power of the theory as well as the legitimacy of the underlying presumptions (Takahashi and Terano, 2003). Predominantly the empirical investigations carried out in 1980's refuted the assumptions of these rational models (Mahmood et al., 2011). These investigations demonstrated that when people or organisations are accompanied with high degree of uncertainty and complexity about choosing an alternative, they behave somewhat differently from rationality, following a new concept of bounded rationality (Tseng, 2006). Thus, in reality people display irrational behavior, as they have preference for some internal standards as against some objective standards (Cummins and Nistico, 2002). These internal standards may be inspired by their values, beliefs, emotions, feelings and intuition, that are all an inherent part of human intellect (Haselton et al., 2005; Kahler, 2007; Keren and Teigen, 2004; Pullen, 2004). In behavioral finance terminology these are called psychological biases or behavioral biases. Studies in economics and psychology have demonstrated that humans are affected by numerous biases in the process of decision making, subsequently driving the decisions to depart from the foremost ideal rational choices (Kahneman and Tversky, 1979). These biases act as drivers and influence our cognitive thinking by making an individual predisposed to behave in an irrational manner. Because of these mental predispositions the decision making is not generally ideal, and the fact that behavioral inclinations without delay affect the optimal choice making is overlooked by various investment experts and financial professionals. In the realms of investments, such biases can have precarious effect and hence understanding them is of significant importance (Byrne and Utkus, 2013).

For the sake of simplicity, this research paper is divided into different sections. Section one describes in detail the rational approach to decision making. Second section discusses the irrational and bounded rationality frameworks. Third section throws light on how people actually handle their decisions and how people form their beliefs. Fourth section discusses how people set up their preferences under the purview of Prospect Theory and its applications. The fifth section analyses the role of emotions and its subsequent impact on investment decision making, and, finally the last section presents the discussion and conclusion of the study.

\section{Objectives of the Study}

This research paper aims at exploring the two distinctive approaches to decision making. In particular, this research study sheds light on how people actually handle their decisions i.e. how individuals form their beliefs and set their preferences under rational as well as irrational approaches of decision making. Further, this research paper mainly aims to explore the deviant behaviors which might 
be caused by psychological factors or behavioral biases, that even though being the ingrained aspects of human decision making, affect the ability to act factually while investing.

\section{Methodology}

The present study adopted the methodology of qualitative economic analysis. Through this methodology, the research investigates the relevant literature that has been discussed both theoretically and empirically and as a result enables the formulation of valid conclusion emerging from this research paper. Further, the research study by inculcating an insightful dialogue discusses a wide array of concepts, theories and philosophies that aim at bringing a deeper understanding of the approaches used in investment decision making.

\section{Rationality Approach of Decision Making}

The rationality doctrine asserts that an individual performs according to his self-interests, has perfect and free access to information in his surroundings, is unbounded in its attention capacity and time, and knows his preferences well and how to decide and act over them. According to Simon (1982):

\section{"Rationality denotes a style of behavior that is appropriate to the achievement of given goals, within the limits imposed by given conditions and constraints. Theories of rational behavior may be normative or descriptive, that is, they may prescribe how people or organizations should behave in order to achieve certain goals under certain conditions, or they may purport to describe how people or organizations do, in fact, behave".}

Similarly, Chandra and Kumar (2008) defined rationality as being reasonable and making unbiased decisions that suit one's interests. Thaler (2005) defined rationality as when people update their profile with new information on recurrent basic, and get ahead with those choices that are acceptable. Markowitz (1952) asserts that investors are characterized by rationality and risk aversion, preferring low risk over high risk for attaining a given level of return. Likewise, the standard economics theory contends that agents handle their information as per Bayes rule. Further, they depend on reasoning and logic for making an optimised decision (Nozick,1993). Mintzberg et al. (1976) proposed a three-stage model for rational decision- making process that incorporates identifying the problem, developing and evaluating of equivalent substitutes to the problems and ultimately choosing the most ideal option. Likewise, Schoenfeld (2011) presented a six-step model for rational decision making process.

Fundamentally, rational decision making process lies in the heart of most of the hypotheses in economics as well as in finance. This whole idea of the rational economic man rests on the basic assumption of homo economicus, that was discussed back in 18th century by Adam Smith in his popular book the "Wealth of Nations". Homo economicus is substantially a simplified version of human conduct, where a decision maker searches exhaustively for all relevant options, analyses entirely all of the pertinent options by comparing the present options with other available options and then ultimately selecting the best optimal alternative (Baltussen, 2009). The roots of the homo economicus assumption fall into the positivistic doctrine of economic methodology that was presented in the form of Expected Utility Theory by Neumann \& Morgenstern (1944), and Subjected Expected Utility Theory of Savage (1954), which estimates the unknown probabilities subjectively (Baltussen, 2009). The main focus of Expected Utility Theory is on rational expectations (Filbeck et al., 2005) which is considered as normative model of rational choice and descriptive model of economic behavior, and governs the exploration of decisions under risk and uncertainty (Kengatharan and Kengatharan, 2014). This was consistently adopted by the massive segment of mainstream financial experts of the second half of the $20^{\text {th }}$ century, representing a strong hold in modern investment theory (Andrikopoulos, 2005).

In order to have a broader understanding of the decision making under rational approach, it is necessary to have a look on the axioms of the homo economicus. First, homo economicus is characterized by perfect self-interest, implying that it attaches value only to the economic outcomes and gets least influenced by facets like mood, feelings, fear or regret. Second, homo economicus rests on risk neutrality or risk averse behavior of an individual. Under this paradigm an individual has disliking for the risk in all situations and over all the stakes he possesses. The third assumption is regarding persistently discounting the future 
payoffs at constant rate. The fourth assumption of homoeconomicus is grounded on the axiom of conditional probabilities which was mathematically introduced in 1763 by the renowned mathematician Thomas Bayes. Bayes proposed a probabilistic framework for making highly structured rational decisions based on all the relevant and available information. Thus, homo economicus optimizes over all possible alternative's and only considers these after fully understanding them.

To summarise, under rational paradigm, decisions are depicted as choices among diverse alternatives that are represented by a series of certain (sure) or multiple potential outcomes to which values are allotted termed as utilities. Each outcome has a certain probability of realising, which is multiplied to it for arriving at decision weights. Finally, that alternative is chosen which has highest decision weight (i.e. utility of the outcome multiplied by the probability of happening it, in case of a certain outcome and submission of highest decision weights i.e. sum of utilities in case of multiple possible outcomes). This can be understood by the following equation.

$\mathrm{U}(x)=E \sum_{i=1}^{n} P\left(x_{i}\right) u\left(x_{i}\right)$

Where $U(x)$ represents the valuation of the decision alternative. $u(x i)$ indicates the expected utility of the outcome (xi). $p(x i)$ is the probability on that outcome, and the expectation encompasses all $n$ possible outcomes.

\section{Irrationality Approach of Decision Making}

Rationality doctrine has dominated the field of economics and modern investment theories for decades. The assumptions of rationality paradigm were regarded as normative and their absence in the models was deemed intolerable, rendering them null and void. However, with the passage of time, the rationality assumptions invited severe criticism from various behaviourists (Nofsinger, 2001). Moreover, these assumptions were practically put into the test in real sense as how individuals actually make their decisions. After testing these assumptions and models, it was realised that the assumption of homo economics is criticised on the fact that the progression of this thought lies in its complex nature as well as its inaptitude prospect to be used efficaciously for exactly anticipating and demonstrating the human behavior itself. On account of simplicity, mathematical modesty and experiential perceptive, the assessment of human conduct was over simplified and evaluated by ensuing methods designed and implemented in the field of hard sciences (Andrikopoulos, 2005). Dinga (2009) argues that rationality itself is difficult to explain in light of the fact that the human conduct is for sure unforeseeable. Rationality emerges because of the fact that orthodox economic science still remains the prisoner of the mechanical paradigm, where one's beliefs, intuition and, ideals are not recognised valuable aspects of the economic methodology. Rationality for behaviourists appeared to be based exclusively upon theoretical assumptions which exist only in Plato's idealistic world (Simon, 1997), where human beings are unable to distinguish between information that requires probabilistic judgement from that which requires value judgement (Andrikopoulos, 2005). Behaviourists argue that people fail to react rationally to new information and do not act like machines that always maximise utility (Kudryavtsev et al., 2013). The reason being that people actually fail to adopt the idealistic mathematical framework, and their capacity to execute multiple tasks at the same time (Kahneman, 1973). For instance, a notable psychological finding is the magical number seven plus or minus two" rule which implies that human beings can handle just seven (plus or minus two) chunks of information at one time (Miller, 1956). Hence, the focus of the researchers, particularly the behaviourists, shifted from idealistic to the more realistic theory of decision making. An early challenge to strict rationality and optimising behavior of people came from Simon (1947) who presented the concept of bounded rationality and satisficing behavior which served as the foundation for most of the decision making theories that had taken after. Simon (1955) notes that;

"the task is to replace the global rationality of economic man with a kind of rational behavior that is compatible with the access to information and the computational capacities that are actually posed by organisms, including man, in the kinds of environments in which organisms lived."

Following an early lead from Simon (1947), later on a number of research studies surprisingly 
have exposed a significant volume of evidences that contradicts this viewpoint. In particular, the investigations conducted by Allais (1953), Bernstein (1996), Ellsberg (1961), Evans (2006), Gao \& Schmidt (2005), Kahneman \& Tversky (1979), Statman (1995, 1999), Thaler (1994) and Tversky \& Kahneman (1974) report lot of cases of recurring patterns of irrational behavior, inconsistency and mistakes in how people settle on making decisions when confronted with ambiguity. Especially, with the advent of Prospect Theory by khaneman \& Tversky (1979) that incorporated reference position for assessing the optimal decision, supplemented the said arguments and added more weight.

\section{Bounded Rationality Approach}

Behavioral economists describe that how people actually think, behave and make economic choices in the real world, and more particularly what exactly happens if the assumption of being rational consistently is relaxed (Thaler, 1994). Bounded rationality theories are inferred from relaxing up a portion of these absolute theoretical assumptions. Thaler (1994) coined the term 'Quasi-rational' for "less than fully rational", or 'trying hard but subject to systematic error' (Thaler, 2000), while Simon (1957) called it "Bounded Rationality" (Systematic deviations from the precepts of normative finance and investor behavior). As per Simon (1997):

"The term 'bounded rationality' is used to designate rational choice that takes into account the cognitive limitations of the decision-maker, limitations of both knowledge and computational capacity. Bounded rationality is a central theme in the behavioral approach to economics, which is deeply concerned with the ways in which the actual decision-making process influences the decisions that are reached."

On the basis of his research, Simon (1947) observed that the optimal decision making is limited, particularly when faced with a problem with regards to certain decision making. Individuals often lack the resources, especially, time to distinguish and evaluate all the potential courses of action before selecting the best alternative for implementation. They also suffer cognitive, environmental and informational constraints. Thus, while deciding about an alternative, human beings have intent to behave rationally which in real sense is not the case. Simon's $(1955,1956,1978)$ theory of Bounded Rationality, called this behavior as 'satisficing' and advocated that people contemplate some threshold of satisfaction instead of maximizing a utility function. In terms of Simon (1956). People generally "satisfice" rather than "optimise" i.e. they select the course of action that fulfils their most significant requirements, even if the decision may not be ideal. Thus, instead of finding an ideal solution, people for the most part try to create a simplified model of the problem. They successively access the most evident choices until they discover one that meets the narrow set of standards and afterward stop their pursuit of tracking down an ideal arrangement. For example, individuals associated with investment actions figure out and interpret investment alternatives that would appear as rational decision making process however, they fail and fall back on basic simplistic models which upshots imperfect choices. Satisficing basically is a type of compelled optimisation that takes into account the effect of reflecting the impact of decision deliberation costs. Satisficing people might be operationally rational (aiming to be reasonable) however aren't necessarily fundamentally rational (attaining ideal results) (Muhammad, 2009). Bounded rationality according to researchers is not same as the irrationality. In other words, market players in general are bounded rational, but not necessarily irrational (Tseng, 2006). Comparable characteristics apply to financial decision making, as this process necessitates both instinct and knowledge acquired from prior experiences. Still, the financial markets are hard to appreciate in light of the fact that there is a significant degree of intricacy in actual world (Gwily, 2009).

\section{How People Handle Decision Making}

Despite the fact that numerous studies have been conducted in this field, yet majority of the people are ignorant with regard to financial behavior and the factors that contribute to irrational behavior (Montier, 2002). Therefore, it becomes more important to visualise how in real sense individuals decide about the alternatives and what factors influence their mind set, so that they deviate from rationality. The answer to these questions can be found if the psychology of the individuals exposed to decision making is studied and understood properly. Psychological research has made a substantial progress in the last three decades, developing robust theories of how people behave, analyse and draw conclusions 
(Bloomfield, 2010). Behavioral finance is the study of how psychological factors impact financial decision making of individuals and business (Nofsinger, 2001). According to Etzioni (2014), behavioral economics assists in understanding and interpreting human behavior as well as their intellectual abilities. These fields demonstrate that people's behavior is grounded on the intellectual model that integrates a variety of interrelated factors including psychology, sociology and finance, and among them there are a plethora of sub factors particularly related to emotions, preferences, perception, intuitions, culture, religion and ideology that triggers irrational decision making (Farlin, 2006; Macgoun, 1992). Thus, in real sense human beings behave differently and act based on their impulses, intuitions, feelings, beliefs and preferences. These subjective terms in behavioral finance literature are termed as biases (behavioral biases or psychological biases), and these are considered errors in decision making (Kahneman and Tversky, 1979). In terms of Shefrin (2007), bias is nothing else but the "predisposition towards error", or "tendency towards a certain disposition or conclusion" (Wolman, 1973). These psychological biases in financial setting were initially identified in 1974 by Daniel Kahneman and Amos Tversky. Further, the literature in behavioral finance portrays these biases in various settings which are as:

- "Systematic Errors in Judgment" (Kahneman and Riepe, 1998).

- "Heuristics (rules of thumb)" (Kahneman and Tversky 1974; Shefrin 2002; Baker and Nofsinger 2002; Prast 2004; Pompian 2006).

- "Beliefs, Judgments or Preferences" (Kahneman and Tversky 1974; Pompian 2006).

Simply put, 'Biases' are the designs of the human intellect and a mechanism employed by the human intellect to make sense of information overload for arriving at a specific decision. The reason being that humans are unable to solve the dynamic optimization problems that arise because of cognitive limits, information processing techniques, or heuristics. (Baker and Nofsinger, 2002; Kahneman and Tversky, 1974; Keren and Teigen, 2004; Pompian, 2006; Prast, 2004; Shefrin, 2002).

There has been considerable amount of research done in this area about how people fall prey to these behavioral biases which affect their investment performance. For example, Montier (2002a, 2002b) claim that People are predisposed to psychological biases when making investments. Similarly, Kahneman \& Tversky (1979) studied investor cognition and discovered that investors are susceptible to cognitive biases, emotions and attitudes that develop over time. Etzoni (2014) pointed out that there are various cognitive biases that limit the intellectual capacities of humans. Pompain (2006) contends that individuals past behavior has a remarkable influence on their future decisions which limit their reasoning and analytics, thus becoming dependent upon beliefs and preferences. Likewise, Shefrin (2002) argues that these beliefs and preferences lead individuals to settle on one sided decisions and are the evidence of existence of irrationality in decision making process. As a result, decision making in personal finance, is influenced by these values and beliefs which serve as filters to narrow down the choices from a range of alternatives. Further, these values and beliefs are collectively considered in the development of the preferences concerning risky choices. Therefore, it becomes fundamental to understand how individuals structure these beliefs, preferences and judgments that drive their financial investment decisions.

\section{How People form Beliefs and Preferences}

Beliefs and preferences guide people's expectations, and expectations turn out to be most important inputs for financial decision making. Generally, people often simplify the complex task of forming expectations and assessing probabilities to simpler judgements by relying on a limited number of 'Heuristics' (Kahneman and Tversky 1974; Tversky and Kahneman, 1974). Heuristics are simple rules of thumb which people often employ to speed up their decision making. This is because people generally possess limited working memory (Miller, 1977), limited investment knowledge and skill (Wang et al., 2006). Thus, they are unable to effectively analyse the plethora of information available in the market. Heuristics reduce the cognitive load and complexities in decision making however, they often fail to manage the full logic of decisions and result in cognitive illusions (Simon, 1955, 1979; Tversky and Kahneman, 1974). It is really not surprising that investors often employ these heuristics in forming expectations and choosing between alternatives, 
but what is more surprising is that investors with requisite knowledge and life long experience of markets, give up the principles of rational analysis and instead rely on these heuristics for forming their decisions (Moser, 1989). Thus, heuristics are a sort of effort shrinking exercise, which integrates limited information by examining only a few clues (Shah and Oppenheimer, 2008). For example, when people are presented with a choice among different alternatives, they do not weigh each of the alternatives, instead they sequentially eliminate those alternatives that do not possess required characteristics (Payne, 1976; Tversky, 1972). Many researchers in the field of financial economics contend that these heuristics influence financial decision making and conduct of financial markets (Abarbanell and Bernard 1992; Debondt and Thaler, 1985, 1990; Klein, 1990). Daniel Kahneman and Amos Tversky appear to be the first one to investigate the factors that make up heuristics, presenting three of them namely: Representativeness heuristics, Availability heuristics and Anchoring heuristics (Kahneman and Tversky, 1974). Waweru et al., (2008) list two more factors to heuristic theory that are Gambler's fallacy and Overconfidence. The detailed discussion of these heuristics biases is presented below.

\section{Representativeness}

This judgemental heuristics contend that people often assess the likelihood of an uncertain event pertaining to a specific set of population by examining how closely the event resembles the characteristics of its parent population, or reflects the mechanism by which it is produced (Kahneman and Tversky, 1972; Kahneman and Tversky, 1974). Individuals rely on this heuristic because they are unable to grasp the fundamentals of forecasting (Khaneman and Tversky, 1974). Representativeness leads people to hypothesize or generalize a phenomenon based only on few attributes (Bazerman and Moore, 2012; Nisbett and Ross, 1980). People affected with this heuristic fall prey of several other important biases which include putting too much weight on recent experiences, Base rate neglect, Sample size neglect, and Conservatism bias, which are discussed below.

\section{Recency Effect}

Due to representativeness, people overstress the most recent evidence and overlook the regular long term rate (Ritter, 2003). People value most recent experiences and consider it as representative of the population without weighing other attributes too. For example, after a few quarters of higher profitability, there arises a chance that investors may wrongly deduce a company's high long term growth rate (Waweru et al., 2008).

\section{Base Rate Neglect}

Second bias is base rate neglect, which is opposite of the above phenomenon, i.e. people place too little weight on base rates or prior probabilities (Khaneman and Tversky, 1972). As per Bar (1980), "the base rate fallacy is people's tendency to ignore base rates in favour of, e.g. Individuating information (when such is available), rather than integrate the two." Hence, when it comes to investment decisions, the decision makers rely on stereotypes, without properly integrating the base likelihood of stereotype occurring (Pompain, 2006).

\section{Sample Size Neglect}

The third bias related to representativeness is sample size neglect which arises when individuals attempt to generalize from too few samples (Barberis and Thaler, 2003) or when people incorrectly assume that small samples are representative of populations (Pompain, 2006). This phenomenon is also called Law of small numbers. However, this small sample data may reflect the current trend but are not able to describe the attributes of whole population. This leads to erroneous investment or disinvestment decision (Khan et al., 2017).

\section{Conservatism Bias}

Conservatism bias occurs when people underrate the influence of fresh evidence which is not indicative of the process from which it is generated (Baltussen, 2009). The reason being that people are sluggish in updating their beliefs as well as in responding to the recent evidence or development (Bakar and Yi, 2016). Pompain (2012) argues that "conservatism causes individuals to overweight base rates and to underreact to sample evidence."

\section{Anchoring and Adjustment Heuristics}

Pompain (2006) defines anchoring bias as a tendency among investors to base their investment decisions to an irrelevant reference point. Generally, people who have to make numerical forecasts tend to employ anchoring heuristics (Tversky and Kahneman, 1974). This cognitive heuristics bias 
results of people's inclination to make judgements based solely on the first piece of information or a specific reference point which may be logically irrelevant (Pompain, 2006). Consequently, when an anchor is set (initial piece of information/ reference point) afterwards all further assessments revolve around that anchor, which is subsequently adjusted to yield final judgement. This initial information may come from a variety of sources such as it may be a given value, computed value, or historical averages etc. However, in many cases the adjustment up or down turns out to be insufficient. This leads to an error in interpreting other details regarding the anchor, since different starting points produce diverse estimations (Khaneman and Tversky, 1974). Anchoring and adjustment bias contribute to range of issues for investors. In general, while making market forecasts, investors prefer to stick too close to the anchored values which makes it difficult for them to adopt to the new information, resulting in unambiguous fault in their calculations (Khan et al., 2017). For example, when a stock price has recently moved to correct the mispricing, investors may still anchor to the previous price patterns and expect it to continue (Baltussen, 2009).

\section{Availability Bias}

Availability bias arises when people assess the likelihood of happening of an event based on how easily the relevant instances come in mind (Tversky and Kahneman, 1973). This cognitive heuristic occurs when individuals make excessive use of readily available information, rather than concentrating on the overall situation. Thus, people overweigh recent information or have a strong inclination for a particular fact as opposed to analysing all information because this particular fact is more easily remembered in their minds (Nofsingera and Varmab, 2013). This heuristic is usually employed when assessing the plausibility of a specific development (Tversky and Kahneman, 1974), and in probabilistic situations to avoid risk. Overreliance on availability heuristics results in various systematic biases inducing people to behave irrationally (Folkes, 1988). Further, intrusion of the laws of probability occur, since all events are not equitably retrievable (Baltussen, 2009). Availability bias is stronger for recent occurrences or events that are more vivid and familiar because they effect perception more easily. Moreover, people overestimate the probability of repeating it for reasons unrelated to its frequency (Sadi et al., 2011).

\section{Overconfidence}

Overconfidence occurs when people have unwarranted faith or unmerited confidence in one's own self judgements, intuitive reasoning and cognitive capabilities (Pomapin, 2006). As per Shefrin (2007), overconfidence "pertains to how well people understand their own abilities and the limits of their knowledge." Pompain (2006) argues, "too many people overvalue what they are not and undervalue what they are", such people are afflicted by overconfidence. This bias generates as individual investors lack the ability to adequately review their initial estimates after receiving new information. Moreover, people ignore to acknowledge by what degree their assessment may be wrong (Simon et al., 2000). Daniel et al. (1998) define it as a sensation where people underestimate the public information signals which are received by all, and overrate the precision of their private information signals. To put it another way, people believe that their information is more accurate than that of others (Ackert, 2014). Thus, overconfidence causes people to exaggerate their experiences and expertise, because they believe that they are better decision makers than others, which is not actually the case (Larrick et al., 2007). This results in miscalibration between the degree of confidence expressed and the subsequent reality (Olsen, 2010). Overconfidence leads investors to take impulsive decisions, therefore, they search for less help and direction in making major decisions. Investors who tend to be overconfident are less likely to generalize information and are more likely to engage in over trading (Shefrin 2002).

\section{Self-Attribution Bias}

Self-attribution bias is a form of overconfidence bias where people attribute accomplishments to their own abilities and aptitudes whereas blaming failure on bad luck (Barberis and Thaler, 2003). Self-attribution bias further strengthens individual's overconfidence, so the subjects who suffer from selfattribution bias will be overconfident in their decisions and judgements. Individuals exposed to this bias contemplate that they have more capabilities compared to an average, also called as "better than average effect" (Svenson, 1981; Taylor and Brown, 1988). According to Gervais \& Odean (2001), people assess their capabilities not through selfexamination but by looking at their achievements and 
failures. As a result, people are more likely to take too much credit for their own achievements which affects their ability to learn from past performances.

\section{Status-Quo Bias}

The term statusquo as defined by Samuelson \& Zeckhauser (1988) means "doing nothing", or "remaining sticky to one's current or previous decisions". Thaler (1980) contends that it is a tendency among people to stick to their own beliefs and considering this state as ideal for the prevalent situation, while under weighing other opportunities. As a result, people who are prone to this bias, frame their opinions about a subject, and are reluctant to undergo any further change which will affect their current state. Besides this, people are likely to choose a suboptimal option, since it was chosen previously (Kempf and Ruenzi, 2006). Tversky \& Shafir (1992) argue that conflicting choice among the alternatives not only increases the likelihood to withhold that choice, but also the likelihood of maintaining the default option (Status-quo). Mostly the participants in retirement programme stay prone to this bias as they prefer to stick with their previous asset allocations despite significant fluctuations in returns (Samuelson and Zeckhauser, 1988).

\section{Gamblers Fallacy}

Gamblers fallacy emerges out as an offshoot of the representativeness heuristics, especially the "law of small numbers" which states that a small sample represents and resembles the characteristics of its parent population from which it is drawn (Barberis and Thaler, 2003: Rabin, 2002; Statman, 1999). Investors are drawn into contrary thinking as they perceive that short sequences of a random event could be representative of a longer event (Rabin, 2002). Gamblers fallacy, according to Khaneman \& Tversky (1972) is based on misinterpretation of the legitimacy of laws of chance. Here the chance is viewed as a "self-correcting process, in which a deviation in one direction induces a deviation in the opposite direction to restore the equilibrium" (Tversky and Kahneman 1974). For example, if a fair coin is flipped ten times, and each time it lands on heads, an investor suffering from this bias believes the next flip will result in tails. Moreover, investors who suffer from gamblers fallacy bias are more likely to be biased in predicting stock price reversals, or trend reversals that are thought to mark the end of good (or poor) market returns (Waweru et al., 2008).

\section{How Individuals Set their Preferences}

How individuals form their preferences and how these preferences are different from those set by homo economicus are well potted in Prospect Theory (Kahneman and Tversky, 1979) and its generalization, Cumulative Prospect Theory (Tversky and Kahneman, 1992). These two theories are currently the finest descriptive theories of decisions under risk (Baltussen, 2009). Prospect Theory being a descriptive model of decision making under risk and uncertainty was introduced by Khaneman and Tversky (1979) as an alternative model to the Expected Utility Theory (EUT). Filbeck et al. (2005) contends that these two theories address two distinct approaches. Prospect Theory emphasizes on subjective decision making and is deeply affected by individual's value system. However, EUT essences on rational expectations of an individual and ignores importance to the value system. Further, EUT is unable to clarify as to why people have preferences for both insurance and gambling. Prospect Theory depict several states of mind intriguing various psychological factors which influence investors decision making process. This theory is about how individuals predict and respond to choices and set their preferences, especially in the world of uncertainty. Prospect Theory and its generalisation Cumulative Prospect Theory has provided various intriguing and important insights related to the psychology of an individual, which are stated below.

First, people are not so much concerned about the final value or the absolute value of their wealth, instead they care about the changes in terms of deviations from reference point. To put it another way, utility/value primarily depends on gains or losses rather than final wealth positions (Kahneman and Tversky, 1979; Markowitz, 1952; Tversky and Kahneman, 1992). Generally, people respond to these deviations from the reference point with decreasing sensitivity, implying that an absolute change of $1 \%$ to $2 \%$, from the reference point is interpreted as a hefty increase than a change from $30 \%$ to $31 \%$ (Baltussen, 2009). Hence, individual's utility functions for the most part are concave for gains (implying risk aversion), and convex for losses (implying risk seeking) (Kahneman and Tversky, 1979). Second, people see losses, those negative 
departures from reference point, altogether different from gains (Kahneman and Tversky, 1979, 1991; Tversky and Kahneman 1992). Third, peoples risk perceptions differ in varying situations ranging between risk neutrality and risk aversion. People prefer risk when it comes to gains and avoid risk when it comes to losses (Kahneman and Tversky, 1979; Tversky and Kahneman, 1992). Further, these circumstances have been well elaborated in Cumulative Prospect Theory which anticipate a distinctive fourfold pattern of risk behaviors- risk aversion (disliking risk) for options that have a high likelihood for low gains and low likelihood for high losses, risk seeking (risk loving) for options that have less probability of happening for a high gain, and high probability of happening for small losses (Baltussen, 2009). Fourth, people systematically depart from weighing consequences by their probability which relates to certainty effect. Generally, people prefer those outcomes that are more definite and likely in nature and underweigh outcomes that have a low probability of occurrence, hence overlooking extremely small probabilities (Kahneman and Tversky, 1979; Tversky and Kahneman, 1992). Waweru et al. (2008) describes Prospect Theory in form of Loss aversion, Regret aversion and Mental accounting, as significant perspectives of mind that individuals use for setting up their preferences which ultimately accounts their decision making as well.

\section{Loss Aversion}

People do not treat losses and gains in linear way, rather there is a tendency among decision makers for avoiding losses. Barberis \& Huang (2001) define loss aversion as a difference in levels of mental penalties, people have for gains or losses. People overweigh losses more heavily, because loses are twice painful as much as gains feel good (Thaler, 1999). However, losses that occur after a prior gain are comparably less painful than the losses that occur after a prior loss (Barberis and Huang, 2001). People are in high distress for the prospect of losses than the delight expressed on identical gains (Barberis and Thaler, 2003).This is because losses tend to loom larger than gains and seem to be more emotionally exuberant. Odean (1998b) contends that loss aversion may be a typical element of investor behavior, yet it ends up being more intense when the problem is framed in negative terms. This causes investors to be in more panic, resulting in poor decision making and loss of investors wealth (Waweru et al., 2008).

\section{Disposition Effect}

This bias stems out from the loss aversion behavior and is generally a trading behavior flaw among investors. Disposition effect refers to the tendency of individual to realise the gains, while being hesitant to realise losses. As a result, investors hold the losing stocks for too long and sell the winning stocks too early (Shefrin and Statman 1985). Barberis \& Xiong (2009) track down that such behavior could be well explained by individuals who fear experiencing losses far more than they enjoy making gains. Summers \& Duxbury (2012) argue that there are some emotions, particularly "regret" is the main reason responsible for disposition effect behavior among investors. In line with this, Shefrin \& Statman (1985) showed that the inclination among investors to stay away from regret and look for pride causes them to sell winners too soon and keep losers exclusively long. According to Nofsinger (2005), selling the "winner" (stock whose price has increased) authenticates a decent choice to buy that stock in the first place and instils pride. Selling the "loser" (the stock showing loss) elicits the realization that the initial decision to buy it was poor, and consequently invigorates regret (Chen et al., 2007).

\section{Mental Accounting}

The term "Mental Accounting" refers to the cognitive process by which people categorise events under different headings and place them in separate mental compartments or mental budgets, based on their superficial attributes (Shiller 1998). Barberis \& Huang (2001) define mental accounting as a "process by which people think about and evaluate their financial transactions". This practice lets an investor to arrange their portfolio into distinct accounts (Barberis and Thaler, 2003; Ritter, 2003). Thus, people organise, analyse and keep track of their financial situation following mental accounting. Moreover, following this practice, helps an individual to overcome the self-control problems (Thaler 1999; Thaler and Shefrin, 1981). People employ some rules in order to categorise events and to track their frequency (Ackert, 2014). However, the differences between these accounts in some cases may often have a greater impacton our behavior than the actual events (Mutswenje, 2009). Thaler (1999) offers an overview of how mental accounting helps in understanding of varied financial behaviors. Thaler (1999) clarifies that even though the cash 
dividends and capital gains have akin tax treatments, an investor possibly prefers cash dividend payments to capital gains. The reason being that the investors who employ the mental accounting principle form separate account heads for each of the category based on their usage. For example, investors might keep cash dividend payments under "current income" account and capital gains might be under "long term savings" head. Doing so, an investor might sense comfort in spending the current income part but not the funds meant for savings (Ackert, 2014). Another example of mental accounting in investment behavior is that investors often are reluctant to sell an investment that once had massive gains and now has mild gains. This reluctance is because investors create separate mental compartments for the gains they had earlier, and this behavior causes them to wait for the arrival of that gainful period (Thaler, 2001).

\section{Framing}

Framing is concerned with how people perceive, organise, interpret, and code a particular set of information and how this affects their decision making. Frames are the mental constructs that assist individuals in organising their thoughts and simplifying details to sort out choices (Russo and Shoemaker, 2002). The frame establishes limits, defines reference points and sets yardsticks that influence what, when and how information could be accessed (Olsen, 2010). Tversky \& Kahneman (1981) introduced the concept of framing, implying that people are subject to cognitive inertia, which means people change their mind and arrive at different responses depending on the way the problem is presented to them. Moreover, people prefer to use only that information which is presented clearly and use it in a manner in which it is displayed (Slovic, 1972). Thus, psychological doctrines that administer decision perceptions as well as assessment of outcomes, yield predictable shifts in people's minds when the same question is presented in a different way. Especially, people's choices are often conflicting when confronted with indistinguishable decision problems that are framed in a positive manner (in terms of gains) versus the problems framed in negative manner (in terms of losses) (Gonzalez et al., 2005). For instance, people adopt a conscious approach when decisions are framed in terms of the number of lives that can be saved rather than presenting the very choices as far as lives that can be lost (Tversky and Kahneman, 1981). Thus, the order in which problems are presented and the degree of difference between them will affect the decision to be taken (Babajide and Adetiloye, 2012). People exhibit this sort of tendency either due to cognition inertia or emotional reasons, prompting them to organise and register the information in different mental structures or frames (Antony and Joseph, 2017).

\section{Narrow Framing}

Narrow framing is subset of the framing concept and is related with integrating decisions in a narrow manner. In fact, the degree to which choices are bracketed or clustered together considerably influences decisions (Read et al., 1999). Generally, there is a tendency among people to integrate decisions more narrowly instead of following a wider frame because people consider decisions one at a time (Kahneman and Lovallo, 1993; Tversky and Kahneman, 1981). To put it another way, if choices are presented to people one at a time, they choose sequentially and bracket them narrowly, however, if several choices are presented, people bracket them broadly (Kahneman, 2003; Read et al 1999; Redelmeier and Tversky, 1992). Henceforth, a set of decisions are grouped together by considering the impact of each decision on the other decisions inside a similar frame or within a same bracket, while overlooking the effect of other decisions outside the bracket. For example, investors in general pay attention to fluctuations in the individual stocks they hold rather than fluctuations in their portfolios. This practice eventually results in suboptimal or unfavourable portfolios (Baltussen and Post, 2007).

\section{Role of Emotions}

Besides these cognitive factors, emotions have a substantial role to play in forming individuals beliefs and preferences. Indeed, there exists a vast evidence which show that emotions influences individuals decision making specifically when encountered with risk and uncertainty (Forgas 1995; Isen 2000; Loewenstein et al., 2001; Schwarz 1998). Greenfinch (2007) defines emotions as "painful or pleasurable feelings which are of mental origin. They contribute to a person's motivations and therefore affect its decisions". Emotions are mental states such as anger, fear, regret, worry, hope, pride, guilt 
etc. that turn out to be drivers of individual's decision making. Moreover, these emotions determine the risk tolerance level of an investor, and help to maintain over the cost of optimization (Charles and Kasilingam, 2016). Emotions, particularly the fear and hope catch up investor's attention, and overwhelm their reasoning power, thus, decisions become more subjective. Generally, individuals having sturdy emotions are often attributed to make poor decisions, particularly those which are of financial nature. There is an ongoing debate over the positive and negative effects of the emotions on the behavior and decision making of individuals. Formerly, behavioral finance literature indicated that cognitive heuristics biases led to mistakes in investor behavior (Gilovich et al., 2002), however, recent psychological research indicates otherwise (Elster 1998; Hermalin and Isen 2000). Right away there is concern among psychologists and economists on the positive role of emotions in financial behavior and decision making (Hopfensitz and Wranik 2008; Loewenstein et al., 2001). For example, Isen (2000) states that even mild emotional states can affect behavior. Damasio (1994) argues that the absence of emotions has extreme effects on individual decision making, particularly when it comes to making optimal decisions. LeDoux (1998) demonstrate that emotion strengthens individual's decision making in two regards. In the first place, emotions push individuals to settle down on some choices, specifically when making that choice is vital. Second, emotion help individuals in making optimal as well as ideal decisions.

\section{Discussion and Conclusion}

In classical era, the decision making was dominated by rationality doctrine encompassing orthodox mechanical thinking. For rationality model as guided by homo economicus assumptions, decisions are made in accordance with the Expected Utility Theory (EUT). Rational decision theory states that people are unbiased in decisions. They acknowledge all facets and restrict their subjective opinions to alter their decision-making process (Shiller and Robert, 2002). Essentiality, the decision maker as anticipated in rational paradigm is unrestricted in its cognitive abilities and competencies. It acts as it were a machine having super intellect, capable of handling vast information processing and computational capabilities (Simon, 1955). However, in the recent decades, the homo economics model invited a severe criticism, since this model being highly reductionist, fails to capture the subsequent reality. Research studies have proven that people are imperfect in their capacities and competencies to collect, process and interpret all the relevant information for deciding the best course of action (Arthur 1994; Conlisk 1996; Simon, 1955,1957,1959,1979). Thus, the cognitive load needed to solve the complicated decision problems often surpasses people's cognitive capabilities (Baltussen, 2009). To overcome these cognitive problems, people generally have a tendency to opt for the simple rules of thumb (Heuristics) for their decision making. The prime outline of heuristics is that individuals end up making quick and fast decisions by relying heavily on non-algorithmic methods rather than following an algorithmic approach. Moreover, research studies conducted in the area of behavioral finance and investor psychology have proven that in real world investors display irrational behavior. For example, investors transact excessively, hold stock without bearing in mind their key worth, rely solely on past performances, follow crowd mentality, maintain their holdings for loss making shares while selling profitable stocks. Likewise, due to lack of knowledge investors' fail to comprehend and apply effectively their own insights to past as well as current information signals. This results in imperfect decision making behavior and upward push to proven mispricing phenomenon (Andrikopoulos, 2005). It has also been observed that the impact of the behavioral aspect of investing is, often been ignored which causes the impact on the investors ability to act objectively when investing. Moreover, research studies in psychology demonstrated that individuals are highly inspired by their values, beliefs, emotions, intuitions when making an investment decision. These terms are collectively called as psychological or behavioral biases, which by acting as a lens in decision makers thought process, form a new pattern in financial decision making. In simple terms biases are systematic deviations from rational thought or an inclination for a particular judgement. Nonetheless, many of these behavioral biases have served us well and provided ways of coping with day to day choices, but they may inflict severe damage in the long run. Even though it might be difficult to find a readymade cure for these psychological biases, 
however, one needs to be aware of these mental cognitions and their effect, so that one can possibly avoid the major pitfalls.

\section{Acknowledgement}

This research received no specific grant from any funding agency in the public, commercial, or notfor-profit sectors.

There is no conflict of interest.

\section{Funding}

The author(s) received no financial support for the research, authorship, and/or publication of this article.

\section{Conflict of Interest}

\section{References}

1. Abarbanell, J.S. and Bernard, V.L. (1992), "Tests of analysts' overreaction/underreaction to earnings information as an explanation for anomalous stock price behaviuor", The Journal of Finance, Vol. 47 No. 3, pp. 1181-1207.

2. Ackert, L. F. (2014). Traditional and behavioral finance. Investor Behavior-The Psychology of Financial Planning and Investing, 25-41.

3. Allais, M. (1953) 'Le comportement de l'hommerationneldevant le risqué: critique des postulatsetaxiomes de l'ecoleAméricaine', Econometrica, Vol. 21, pp.503-546 (Translation).

4. Andrikopoulos, P. (2005). Modern finance vs. behavioural finance: an overview of key concepts and major arguments. Behavioural Finance: An Overview of Key Concepts and Major Arguments (June 2005).

5. Antony, A., \& Joseph, A. I. (2017). Influence of behavioural factors affecting investment decision-An AHP analysis. Metamorphosis, 16(2), 107-114.

6. Arthur, W. B., 1994, Inductive Reasoning and Bounded Rationality, American Economic Review 84, 406-411.

7. Babajide, A. A., \&Adetiloye, K. A. (2012). Investors' behavioural biases and the security market: An empirical study of the Nigerian security market. Accounting and Finance Research, 1(1), 219-229.

8. Bakar, S., \& Yi, A. N. C. (2016). The impact of psychological factors on investors' decision making in malaysian stock market: a case of Klang Valley and Pahang. Procedia Economics and Finance, 35, 319-328.

9. Baker, H.K. and Nofsinger, J.R. (2002), "Psychological biases of investors", Financial Services Review, Vol. 11, pp. 97-116.

10. Baltussen, G. (2009). Behavioral Finance: An
Introduction SSRN Electronic Journal. https:// doi.org/10.2139/ssrn.1488110

11. Baltussen, G., and G. T. Post, 2007, Irrational Diversification, Working Paper, http://ssrn.com/ abstract $=625942$

12. Barberis, N, and W. Xiong, 2009, What Drives the Disposition Effect? An Analysis of a Longstanding Preference-based Explanation, Journal of Finance 64, 751-784.

13. Barberis, N., \& Huang, M. (2001). Mental Accounting, Loss Aversion, and Individual Stock Returns. The Journal of Finance, 56(4), 1247-1292. http://dx.doi.org/10.1111/00221082.00367

14. Barberis, N., \&Thaler, R. (2003). A survey of behavioral finance. In Constantinides, G., Harris, M., \&Stulz, R.(Eds.), Handbook of the Economics of Finance. Amsterdam: NorthHolland.

15. Bar-Hillel, M. (1980). The base-rate fallacy in probability judgments. ActaPsychologica, 44(3), 211-233.

16. Bayes, T. (1763). LII. An essay towards solving a problem in the doctrine of chances. By the late Rev. Mr. Bayes, FRS communicated by Mr. Price, in a letter to John Canton, AMFR S. Philosophical transactions of the Royal Society of London, (53), 370-418.

17. Bazerman, M.H. and Moore, D.A. (2012), "Judgment in managerial decision making", Wiley Global Education, NJ.

18. Bernstein, P.L. (1996) Against the Gods, John Wiley and Sons Press, New York.

19. Bloomfield, R. J. (2010). Traditional vs. behavioral finance. Johnson School Research Paper Series, (22-2010).

20. Byrne, A., \&Utkus, S. P. (2013). Behavioural finance. Understanding how the mind can help or hinder investment success, UK. Retrieved 
March, 20, 2019.

21. Chandra, A., \& Kumar, R. (2008). Decision Making in the Stock Market: Incorporating Psychology with Finance. In the Proceedings of the Conference on Forecasting Financial Markets in India at IIT Kharagpur, India. December2008 (Availableat:h\#p://ssrn.com/ abstract=1501721).

22. Charles, A., \&Kasilingam, R. (2016). Impact of selected behavioral bias factors on investment decisions of equity investors. Ictact Journal on Management Studies, 2(2), 297-311.

23. Chen, G., Kim, K. A., Nofsinger, J. R., \&Rui, O. M. (2007). Trading performance, disposition effect, overconfidence, representativeness bias, and experience of emerging market investors. Journal of Behavioral Decision Making, 20(4), 425-451.

24. Conlisk, J., 1996, Why Bounded Rationality? Journal of Economic Literature 34, 669-700.

25. Cummins, R. A. and H. Nistico (2002), "Maintaining Life Satisfaction: The Role of Positive Cognitive Bias." Journal of Happiness Studies, 3 pp. 37-69.

26. Damasio, A. R. (1994). Descartes' error: Emotion, rationality and the human brain, Quill.

27. Daniel, K., Hirshleifer, D. and Subrahmanyam, A. (1998), "Investor psychology and security market under and overreactions", The Journal of Finance, Vol. 53 No. 6, pp. 1839-1886.

28. DeBondt, W.F. and Thaler, R.H. (1990), "Do security analysts overreact?", The American Economic Review, pp. 52-57.

29. DeBondt, W.F.M. and Thaler, R. (1985), "Does the stock market overreact?", Journal of Finance, Vol. 40 No. 3, pp. 793-805.

30. Dinga, E. (2009) Studii de economie. EdituraEconomică, Bucure $\square$ ti

31. Ellsberg, D. (1961) 'Risk, ambiguity and the savage axioms', Quarterly Journal of Economics, Vol. 75, pp.643-669.

32. Elster, J. (1998). Emotions and economic theory. Journal of economic literature, 36(1), 47-74.

33. Etzioni, A. (2014). Humble Decision-Making Theory, Public Management Review, Public Management Review,

34. Evans, D.A. (2006) 'Subject perceptions of confidence and predictive validity in financial cues', Journal of behavioural Finance, Vol. 7, No. 1, pp.12-28.
35. Farlin, J. D. (2006). Antecedents and Consequences of Heuristic Biases: Evidence from Individual Investors and Small Business Owners, Pro-Quest Information. $5^{\text {th }}$ Edition. Italy: Pearson Education Limited.

36. Filbeck, G., Hatfield, P. and Horvath, P. (2005) 'Risk aversion and personality type', Journal of Behavioral Finance, Vol. 6, No. 4, pp.170-180.

37. Folkes, V.S. (1988), "Recent attribution research in consumer behavior: a review and new directions", Journal of Consumer Research, Vol. 14 No. 4, pp. 548-565

38. Forgas, J. P. (1995). Mood and judgment: the affect infusion model (AIM). Psychological bulletin, 117(1), pp. 39-66.

39. Gao, L. and Schmidt, L. (2005) 'Self is never neutral: why economic agents behave irrationally', Journal of Behavioral Finance, Vol. 6 No. 1, pp.27-37.

40. Gervais, S. and Odean, T. (2001). "Learning to Be Overconfident", The Review of Financial Studies, vol. 14, no. 1, pp. 1-27

41. Gilovich, T., Griffin, D., \&Kahneman, D. (Eds.). (2002). Heuristics and biases: The psychology of intuitive judgment. Cambridge university press. pp. 16-19.

42. GONZALEZ, C.; DANA, J.; KOSHINO, H. and JUST, M. (2005). "The framing effect and risky decisions: Examining cognitive functions with fMRI". Journal of Economic Psychology, Vol. 26, No. 1, pp.1.

43. Greenfinch, P. (2007), Introduction and Main Concepts: BF vs. EMH. Retrieved from http:// perso.orange.fr/pgreenfinch/bfdef.htm

44. Gwily, M. R., (2009). Can behavioral finance model account for historical asset prices? UK: Cardiff Economics Working Papers.

45. Haselton, M.G., Nettle, D. and Andrews, P. (2005), "The evolution of cognitive bias", in Buss, D.M. (Ed.), Handbook of Evolutionary Psychology, Wiley, New York, NY.

46. Hermalin, B. E., \&Isen, A. M. (2000). The effect of affect on economic and strategic decision making. USC CLEO Research Paper, (C01-5).

47. Hopfensitz, A., \&Wranik, T. (2008). Psychological and environmental determinants of myopic loss aversion, Toulouse School of EconomicsGREMAQ, CISA-Swiss Center on Affective Sciences, MPRA Paper, pp. 1-29

48. Isen, A. M. (2000). Positive affect and decision making. Handbook of Emotions. M. Lewis and 
JM Haviland-Jones.

49. Kafayat, A. (2014). Interrelationship of biases: effect investment decisions ultimately. Theoretical \& Applied Economics, 21(6).

50. Kahler, R. (2007). Beyond the Numbers: Financial Planners are Looking to the Principles of Psychology to Help Them Communicate with Clients About More Than Just Money. Financial Planning, 7(1).

51. Kahneman, D, 2003, Maps of Bounded Rationality: Psychology for Behavioral Economics, American Economic Review 93, 1449-1475

52. Kahneman, D. and Tversky, A. (1974), "Judgment under uncertainty: heuristics and biases”, Science, Vol. 185 No. 4157, pp. 112431.

53. Kahneman, D. and Tversky, A. (1979), "Prospect theory: an analysis of decision-making under risk", Journal of Econometrica, Vol. 47 No. 2, pp. 263-291.

54. Kahneman, D., \&Riepe, M. W. (1998). Aspects of investor psychology. Journal of portfolio management, 24(4), 52-65

55. Kahneman, D., 1973,. Attention and Effort. Englewood Cliffs, NJ: Prentice-Hall.

56. Kahneman, D., and A. Tversky, 1972, Subjective Probability: A Judgment of Representativeness, Cognitive psychology 3, 430-454.

57. Kahneman, D., and A. Tversky, 1991, Loss Aversion in Riskless Choice: A ReferenceDependent Model, Quarterly Journal of Economics 106, 1039-1061.

58. Kahneman, D., and D. Lovallo, 1993, Timid choices and bold forecasts: A cognitive perspective on risk taking, Management Science 39, 17-31.

59. Kempf, A., \&Ruenzi, S. (2006). Status quo bias and the number of alternatives: an empirical illustration from the mutual fund industry. Journal of Behavioral Finance, 7(4), 204-213. http:// dx.doi.org/10.1207/s15427579jpfm0704_3

60. Kengatharan, L., \&Kengatharan, N. (2014). The influence of behavioral factors in making investment decisions and performance: Study on investors of Colombo Stock Exchange, Sri Lanka. Asian Journal of Finance \& Accounting, 6(1), 1.

61. Keren, G. and Teigen, K.H. (2004), "(Yet) another look at the heuristics and biases research program", in Koehler, D.J. and Harvey,
N. (Eds), Blackwell Handbook of Decision Making, Blackwell, Oxford, pp. 89-109.

62. Khan, H. H., Naz, I., Qureshi, F., \&Ghafoor, A. (2017). Heuristics and stock buying decision: Evidence from Malaysian and Pakistani stock markets. Borsa Istanbul Review, 17(2), 97-110.

63. Kim, K. A., \&Nofsinger, J. R. (2008). Behavioral finance in Asia. Pacific-Basin Finance Journal, 16(1), 1-7. doi:10.1016/j.pacfin.2007.04.001

64. Klein, J.T. (1990), Interdisciplinarity: History, Theory, and Practice, Wayne State University Press, Wayne.

65. Kudryavtsev, A. Cohen G. \& Hon-Snir, S., (2013). "Rational" or "Intuitive": Are Behavioral Biases Correlated Across Stock Market Investors? Contemporary economics Vol. 7 Issue 2, 31-53

66. Larrick, R.P., Burson, K.A. and Soll, J.B. (2007), "Social comparison and confidence: when thinking you're better than average predicts overconfidence (and when it does not)", Organizational Behavior and Human Decision Processes, Vol. 102 No. 1, pp. 76-94.

67. LeDoux, J. (1998). The emotional brain: The mysterious underpinnings of emotional life. Simon and Schuster.

68. Loewenstein, G., E. U. Weber, C. K. Hsee and N. Welch, 2001, Risk as Feelings, Psychological bulletin 127, 267-286.

69. Loewenstein, G., E. U. Weber, C. K. Hsee and N. Welch, 2001, Risk as Feelings, Psychological bulletin 127, 267-286.

70. Mahmood, A., Mahmood, A., \&Tabassum, A. (2011). Ethnomedicinal survey of plants from District Sialkot, Pakistan. J Appl Pharm, 3, 212-220.

71. Markowitz, H.M. (1952) Portfolio Selection. Journal of Finance, 7, 77-91.

72. Mcgoun, E. G. (1992). On Knowledge of Finance. International Review of Financial Analysis, 1(3), 161- 177.doi:10.1016/1057-5219 (92)90002-L

73. Miller, E. M. (1977). Risk, uncertainty, and divergence of opinion. The Journal of finance, 32(4), 1151-1168.

74. Miller, G. A., 1956, The magical number seven plus or minus two: Some limits on our capacity for processing information. Psychological Review 63, 81-97

75. Mintzberg, H., Raisinghani, O. and Theoret, A. (1976), "The structure of unstructured decision 
processes", Administrative Science Quarterly, Vol. 21, pp. 246-275.

76. Montier, J. (2000) a. Behavioural Finance: Insights into Irrational Minds and Markets, Wiley Finance New York, NY.

77. Montier, J. (2002) b. Darwin's Mind: The Evolutionary Foundations of Heuristics and Biases. Available at SSRN 373321. doi:10.2139/ ssrn.37332

78. Montier, J. (2002). Behavioral Investing a Practitioners Guide to Applying Behavioral Finance. John Wiley \& Sons.

79. Moser, D.V. (1989), "The effects of output interference, availability, and accounting information on investors' predictive judgments", Accounting Review, Vol. 64 No. 3, pp. 433-448.

80. Muhammad, N. M. N. (2009). Behavioural finance vs traditional finance. Adv. Manage, 2(6), 1-10.

81. Mutswenje, V. S. (2009). A survey of the factors influencing investment decisions: the case of individual investors at the NSE (Doctoral dissertation, University of Nairobi).

82. Narayan, S.M \& Corcoran-Perry, S. (1997). Line of reasoning as a representation of nurses' clinical decision-making. Research in Nursing \& Health, 20, 353-364.

83. Nisbett, R.E. and Ross, L. (1980), "Human inference: strategies and shortcomings of social judgment", Prentice-Hall, Englewood Cliffs, NJ.

84. Nofsinger, J., 2005. The Psychology of Investing (2nd ed.). Upper Saddle River, NJ: Pearson Prentice Hall;

85. Nofsinger, John R. (2001). Investment madness: how psychology affects your investing - and what to do about it. USA: Pearson Education.

86. Nofsingera, J. R., Varmab, A., 2013. Availability, Recency and Sophistication in the Repurchasing Behavior of Retail Investors. Journal of Banking \& Finance 37(7), 2572-2585.

87. Nozick, R. (1993), The Nature of Rationality, Princeton University Press, Princeton.

88. Odean, T. (1998b) 'Volume, volatility, price and profit when all trades are above average', Journal of Finance, Vol. 53, pp.1887-1934.

89. Olsen, R. A. (2010). Toward a theory of behavioral finance: implications from the natural sciences. Qualitative Research in Financial Markets, 2(2), 100-128.

90. Payne, J. W., 1976, Task Complexity and Contingent Processing in Decision Making:
An Informational Search and Protocol Analysis, Organizational Behavior and Human Performance 16, 366-387.

91. Pompain, M.M. (2006), Behavioral Finance and Wealth Management (How to Build Optimal Portfolio That Account for Investor Biases), 1st ed., John Wiley \& Sons, New Jersey, Canada.

92. Pompian, M. M. (2012). Behavioral finance and investor types: managing behavior to make better investment decisions. John Wiley \& Sons.

93. Prast, H. M. (2004). Investor psychology: A behavioural explanation of six finance puzzles. Amsterdam: De Nederlandsche Bank.

94. Pullen, C. (2004), "An introduction to integral finance", Journal of Financial Planning, September.

95. Rabin, M. (2002). Inference by believers in the law of small numbers. Quarterly Journal of Economics, 117(3), 775-816. http://dx.doi. org/10.1162/003355302760193896

96. Read, D., G. Loewenstein, and M. Rabin, 1999, Choice bracketing, Journal of Risk and Uncertainty 19, 171-197.

97. Read, D., G. Loewenstein, and M. Rabin, 1999, Choice bracketing, Journal of Risk and Uncertainty 19, 171-197.

98. Redelmeier, D., and A. Tversky, 1992, On the framing of multiple prospects, Psychological Science 3, 191-193.

99. Ritter, J. R. (2003). Behavioral Finance. PacificBasin Finance Journal, 11(4), 429-437.

100. Russo, J.E. and Shoemaker, P. (2002), Winning Decisions, Doubleday Press, New York, NY.

101.Sadi, R., Asl, H. B., Rostami, M. R., Gholipour, A., \&Gholipour, F. (2011). Behavioral Finance: The Explanation of Investors' Personality and Perceptual Biases Effects on Financial Decisions. International Journal of Economics and Finance, 3(5), 234-241.

102. Samuelson, W., and R. Zeckhauser, 1988, Status Quo Bias in Decision Making, Journal of Risk and Uncertainty 1, 7-59.

103. Sanglier, M., Romain, M., \&Flament, F. (1994). A behavioral approach of the dynamics of financial markets. Decision support systems, 12(4-5), 405-413.

104.Savage, L. J., (1954), The Foundations of Statistics,. New York, NY: Wiley

105.Schoenfeld, A.H. (2011), How We Think: A Theory of Goal-Oriented Decision Making and its Educational Applications, Routledge, New 
York, NY.

106. Schwarz, N. (1998). Warmer and more social: Recent developments in cognitive social psychology. Annual Review of Sociology, 24(1), 239-264.

107.Shah, A.K. and Oppenheimer, D.M. (2008), "Heuristics made easy: an effort reduction framework", Psychological Bulletin, Vol. 134 No. 2, p. 207.

108. Shefrin, H. (2002), Beyond Greed and Fear: Understanding Behavioral Finance and the Psychology of Investing, Harvard Business School Press, Boston, MA.

109.Shefrin, H. (2007). Behavioral corporation finance: decisions that create value, McGraw Hill/Irwin. New York,

110. Shefrin, H. and Statman, M. (1985), "The disposition to sell winners too early and ride losers too long: theory and evidence", Journal of Finance, Vol. 40 No. 3, pp. 777-779.

111. Shiller, \& Robert, J. (2002). From Efficient Markets Theory to Behavioral Finance. Journal of Economic Perspectives 17(1): 83-104.

112. Shiller, R. J. (1998). Human behavior and the efficiency of the financial system, Working Paper No. W6375 (pp. 1305-1340). National Bureau of Economic Research.

113. Simon, A. (1997) Models of Bounded Rationality, Vol. 3, Empirically Grounded Economic Reason, Cambridge: The MIT Press.

114.Simon, H. A., 1955, ABehavioral Model of Rational Choice, Quarterly Journal of Economics 69, 99-118.

115. Simon, H. A., 1957, Models of man, New York: Wiley \& Sons.

116. Simon, H. A., 1959, Theories of DecisionMaking in Economics and Behavioral Science, American Economic Review 49, 253-283.

117. Simon, H. A., 1979, Rational Decision Making in Business Organizations, American Economic Review 69, 493-513.

118. Simon, H.A. (1956), "Rational choice and the structure of the environment", Psychological Review, Vol. 63 No. 2, pp. 129-138.

119. Simon, H.A. (1982) Models of Bounded Rationality, Vol. 2, Behavioral Economics and Business Organization, Cambridge: The MIT Press.

120.Simon, Herbert A. (1947). Administrative Behavior: A Study of Decision-Making Processes in Administrative Organization (1 $1^{\text {st }}$ ed.). New York: Macmillan.

121.Simon, Herbert A. 1978. "Rationality as Process and as Product of Thought." American Economic Review 68:2, 1-16.

122.Simon, M., Houghton, S.M. and Aquino, K. (2000), "Cognitive biases, risk perception, and venture formation: how individuals decide to start companies", Journal of Business Venturing, Vol. 15 No. 2, pp. 113-134

123.Slovic, P., (1972), Information Processing, Situation Specificity, and the Generality of Risk- Taking Behavior. Journal of Personality and Social Psychology 22, 128-134.

124. Statman, M. (1995) 'Behavioral finance versus standard finance', Conference Proceedings of the 'Behavioral Finance and Decision Theory in Investment Management' Conference, Conducted by AIMR, Charlottesville, Association for Investment Management and Research, VA.

125. Statman, M. (1999) 'Behavior finance: past battles and future engagements', Financial Analysts Journal, Vol. 55, No. 6, pp.18-27.

126.Svenson, O. (1981). "Are we all Less Risky and More Skillful than our Fellow Drivers?", ActaPsychologica, no. 47, pp. 143-148

127. Takahashi, H., \&Terano, T. (2003). Agent-based approach to investors' behavior and asset price fluctuation in financial markets. Journal of artificial societies and social simulation, 6(3).

128. Taylor, S. and Brown, J. (1988). "Illusion and well-being: A Social Psychology Perspective on Mental Health", Psychological Bulletin, no. 103, pp.193-210

129. Thaler, (2001), Theory of mental accounting. New York: Academic Press.

130. Thaler, R. (1980), "Toward a positive theory of consumer choice", Journal of Economic Behavior and Organisation, Vol. 1 No. 1, pp. 39-60.

131. Thaler, R. H. (1999). The end of behavioral finance. Financial Analysts Journal, 55(6), 12-17.

132. Thaler, R., and H. Shefrin. 1981. "An Economic Theory of Self-Control." Journal of Political Economy, vol. 89, no. 2 (April):392-410.

133. Thaler, R.H. (1994). Quasi-Rational Economics, Russell Sage Foundation, New York.

134. Thaler, R.H., (2005). Advances in Behavioral Finance, Volume II. USA: Princeton University Press.

135. Thaler, R.H., 2000, 'From Homo Economicus 
to Homo Sapiens', Journal of Economic Perspectives, vol. 14, no. 1, pp. 133-141.

136. Thaler, Richard H. 1999. "Mental Accounting Matters." Journal of Behavioral Decision Making $12: 3,183-206$.

137.Tseng, K. C. (2006). Behavioral finance, bounded rationality, neuro-finance, and traditional finance. Investment Management and Financial Innovations, 3(4), 7-18

138. Tversky, A. and Kahneman, D. (1973), "Availability: a heuristic for judging frequency and probability", Cognitive Psychology, Vol. 5 No. 2, pp. 207-232.

139. Tversky, A. and Kahneman, D. (1974) 'Judgment under uncertainty: heuristics and biases', Science, Vol. 11, pp.24-31.

140.Tversky, A., 1972, Elimination by aspects: A theory of choice", Psychological review 79, 281-299.

141. Tversky, A., and D. Kahneman, 1981, The Framing of Decisions and the Psychology of Choice, Science 211, 453-458.

142. Tversky, A., and D. Kahneman, 1992, Advances in Prospect Theory: Cumulative Representation of Uncertainty, Journal of Risk and Uncertainty 5, 297-323.

143.Tversky, A., Shafir, E., 1992. Choice under conflict: the dynamics of deferred decision. Psychol. Sci. 3 (6), 358-361.

144. Von Neumann, J., and O. Morgenstern, 1944, Theory of Games and Economic Behavior. Princeton, NJ: Princeton University Press.

145.Wang, X. L., Shi, K., \& Fan, H. X. (2006). Psychological mechanisms of investors in Chinese Stock Markets. Journal of Economic Psychology, 27(6),762-780. http://dx.doi. org/10.1016/j.

146.Waweru, N., M., Munyoki, E., \&Uliana, E. (2008). The effects of behavioral factors ininvestment decision-making: a survey of institutional investors operating at the Nairobi Stock Exchange. International Journal of Business and Emerging Markets, 1(1), 24-41. http://dx.doi.org/10.1504/IJBEM.2008.019243

147.Wolman, B.B. (1973), Dictionary of Behavioral Science, Van Nostrand Reinhold Company, 